\title{
INTRODUCCIÓN A DOSSIER BIOPOLÍTICA Y FILOSOFÍA
}

\author{
Introduction to Dossier Biopolitics and Philosophy
}

\author{
VANESSA LEMM \\ Universidad Diego Portales
}

\section{MIGUEL VATTER}

Universidad Diego Portales

Este dossier sobre biopolítica y filosofía comienza con una entrevista de Roberto Esposito, uno de los más prolíficos e importantes exponentes de teoría política contemporánea italiana. En su trabajo, Esposito plantea que las categorías a través de las cuales, en los tiempos modernos, se ha concebido la política -categorías que se centran en el paradigma del contrato social- han agotado su significado y propone la necesidad de repensar, en formas nuevas, la relación entre individuo y comunidad. En sus libros más recientes, una trilogía compuesta por Communitas (2003), Immunitas (2005) y Bios (2007), Esposito desarrolla la tesis que el sujeto moderno, el individuo, con todos sus derechos civiles y políticos, así como sus poderes morales, emerge en sí mismo como el intento de alcanzar inmunidad del contagio de aquello que sobrepasa al individuo, es decir, la comunidad. De acuerdo a Esposito, la filosofía política moderna intenta inmunizar la vida del individuo contra la vida de la comunidad, o vida común, pero termina destruyendo al individuo mismo en una especie de reacción autoimmune. La forma política que asume este síndrome autoinmune de la modernidad es la biopolítica.

El término comunidad deriva de la raíz latina munus, que significa una obligación de dar de sí mismo para los otros. Esposito arguye que no existe comunidad entre individuos sin presuponer, como tal, un don asimétrico o gasto. A la vez, este gasto requerido por la comunidad representa un grave riesgo para sus miembros, toda vez que es un don sin límites, que no puede ser negociado y que no es objeto de un contrato. En el escenario de estas condiciones comunitarias, la política y filosofía social moderna desarrollan lo que Esposito llama "un paradigma inmunitario". Este paradigma estipula que dado el riesgo que la comunidad representa para los individuos que pertenecen a ella, los miembros de la comunidad necesitan defenderse de este estar en común, de esta comunidad de la cual ellos mismos son una parte esencial. Esta autodefensa toma la forma de immunitas jurídica, una inmunidad legal o derecho que el individuo asume respecto de la demanda y el deber que la comunidad le impone a él o ella. Immunitas tiene la misma raíz que comunitas, es decir, munus o don, pero significa la negación de este don; de ahí los diferentes mecanismos político-jurídicos centrados en el paradigma del intercambio de derechos en un contrato a través del cual la vida del individuo busca la protección del Estado contra las demandas de su propia vida 
común. Así, de acuerdo a Esposito, la modernidad desarrolla un concepto de política que en realidad es más bien un ataque a la política. La política inmunitaria asume la forma de autoinmunidad. ${ }^{1}$

Con Bios, la tercera y última parte de la trilogía, Esposito explica por qué la política moderna basada en la protección de la vida es también fundamentalmente una política de muerte, una tanatopolítica, por qué requiere que la política adopte siempre decisiones de vida y muerte: que parte de la especie humana puede ser seleccionada y exterminada para que otra parte pueda seguir viviendo. Esto se transforma en la fundamental cuestión biopolítica que dio pie a la respuesta totalitaria estructurada en términos del racismo de Estado, eugenesia y genocidio. Pero para Esposito, formas de gubernamentalidad antitotalitarias y liberales no se libran de su cuota de decisiones de carácter thanato-políticas, como ha sido tematizado recientemente por varios pensadores quienes han traído a la palestra la posibilidad de eugenesia liberal. ${ }^{2}$ Para Esposito, la filosofía política no puede retornar a una época anterior a la biopolítica. Nace de esto la pregunta respecto si una biopolítica afirmativa, es decir, una política que no es un poder sobre la vida pero una política de la vida misma, es en verdad concebible. Esta pregunta anima también las otras contribuciones a este dossier.

"Biopolítica y Filosofía. Entrevista a Roberto Esposito" vuelve a visitar algunos de los temas centrales tratados por Esposito en su trabajo. En particular desea ahondar nuestro conocimiento sobre la cuestión de la biopolítica y su situación respecto de las tradiciones de la filosofía moderna, la relación entre ideologías políticas del siglo XX y el surgimiento de la biopolítica; y finalmente, los tipos de conceptos de vida que están en juego en la biopolítica.

"Sobre la vitalidad del poder: consideraciones a partir de Foucault y Canguilhem" por Maria Muhle es una contribución original a la literatura sobre biopolítica, porque responde a una pregunta que no ha sido hasta la fecha explorada, es decir: ¿cuál es el concepto de vida que Foucault presupone en su concepto de "biopolítica"? El silencio relativo de Foucault respecto a esta pregunta fue respondido por teóricos subsecuentes como Giorgio Agamben y Toni Negri, quienes han construido conceptos alternativos de vida biopolítica: la idea de "vida desnuda" en el caso de Giorgio Agamben (1998) y la idea de "vida productiva" de Toni Negri (2000 y 2004). Muhle se distancia de tales construcciones porque parecen referirse a una sustancia transhistórica de una "filosofía de vida", en vez de manifestaciones de vida actuales, históricas y empíricas que resultan de la aplicación de tecnologías de biopoder.

Muhle argumenta que la noción de vida de Foucault está tomada del desarrollo de la biología como discurso científico del siglo XIX. Este desarrollo ha sido el objeto de estudio de Canguilhem, uno de los filósofos de la biología cruciales del siglo XX y una importante influencia en el pensamiento de Foucault. En particular, Canguilhem argumenta que en la biología moderna, el fenómeno de la vida es caracterizado por una bipolaridad: en un 
polo, el fenómeno de la vida es caracterizado por las diferencias entre un estado normal y un anormal o estado patológico; estar vivo significa poder enfermarse y recobrar la salud. En el otro polo, el fenómeno de la vida es igualmente caracterizado por su capacidad para crear sus propias normas, algo que Canguilhem llama "normatividad biológica".

De acuerdo con esta concepción de vida biológica, Muhle argumenta que el poder biopolítico no es simplemente un poder que impone normas foráneas sobre la vida biológica desde afuera y, por lo tanto, "oprime" o "domina" la vida. Por el contrario, lo específico del biopoder es que las normas que él aplica a la vida biológica son "imitaciones" de la manera en que la vida es -espontáneamente- normativa, creadora de nuevas normas. Así, por ejemplo, las teorías económicas del laissez faire generan normas que presuponen que la economía opera como un organismo biológico autoregulado, un organismo que se da a sí mismo sus propias normas y su propio criterio de salud y que por lo tanto no debiera interferirse de manera directa. Esto es así por que el biopoder "regula" de una manera que es mucho más interna al objeto de la regulación, y mucho más "libre" que otras formas de poder donde la regulación es siempre impuesta de manera externa al objeto y no deriva de la normatividad interna del objeto. El artículo de Muhle concluye que la concepción de biopoder de Foucault sigue la bipolaridad de la vida biológica: entendido como poder "sobre" la vida, que siempre privilegia la caracterización de la vida biológica que apunta hacia un estado "normal". Biopoder, en este sentido, es poder de normalización. Pero si es entendido como poder "de" la vida, el biopoder de Foucault recobra un sentido de resistencia hacia la normalización, en tanto que privilegia el carácter inmanente normalizador de la vida biológica.

"La ciudad apestada, Neoliberalismo y Pospanóptico" de Rodrigo Castro es un artículo que discute los últimos intentos de Foucault de concebir al liberalismo y al neoliberalismo como la matriz de la biopolítica moderna. Una de las cuestiones centrales no resueltas de la obra de Foucault dice relación con el significado del cambio en su trabajo desde el poder disciplinario hacia el biopoder. ¿Hay continuidad o discontinuidad entre ambos tipos de poder? Como es bien sabido, el poder disciplinario es ejemplificado por Foucault con la imagen del panóptico, el infame diseño de Jeremy Bentham de una prisión cuyos internos son controlados por sí mismos, simplemente en virtud de su conciencia de estar constantemente observados por un agente de vigilancia, quien, a su vez, es invisible para ellos. Pero ¿hay una tecnología de control análoga que corresponda al surgimiento del biopoder?

Según Castro, la biopolítica desarrolla una forma de poder que se basa en la aseguración (securitization) de la vida de los individuos, más que en su disciplinamiento. Lo que los individuos quieren del gobierno es asegurar su movilidad: movilidad de los cuerpos, movilidad del dinero, pero especialmente de los deseos. Para proveer esta seguridad, como sostiene Castro, la gubernamentalidad neoliberal introduce un control, sobre el espacio y el tiempo, que es estructurado siguiendo una línea "postpanoptica", esto es, estructurado de una manera sinóptica. La biopolítica es caracterizada por una forma de poder sinóptico, donde los individuos se transforman en observadores o espectadores, en vez de observados (como en el panoptismo). El cómo llegan a transformarse en sujetos 
de observación sigue una lógica de división espacial, una separación de lo sensible, como dijera Jacques Rancière, ${ }^{3}$ que gira en torno a la distinción entre lo global versus lo local, siguiendo la terminología de Zigmund Bauman. Ser un sujeto global es vivir en ambientes donde es seguro mirar y desear, en esferas de movilidad que no están enraizadas en territorios particulares, sino más bien, siguiendo una idea de Peter Sloterdijk, flotan como burbujas en la superficie de la tierra. ${ }^{4}$ Ser un sujeto particular, de otro lado, es estar segregado y concentrado en un espacio que es territorializado hasta el extremo, como un ghetto urbano o como la franja de Gaza. El poder sinóptico, entonces, divide lo común, el espacio publico ya no más acorde a la división público/privado, sino a las divisiones correspondientes, por ejemplo, a autopistas virtuales de la comunicación (world wide web) y a áreas de confinamiento extranacionales (Guantánamo).

Hannah Arendt es, probablemente, la pensadora del siglo XX que más fuertemente abogó por el retorno del espacio público en nuestras vidas políticas, a efecto de resistir la privatización característica de la gubernamentalidad liberal de la vida y el espacio. Recientemente el pensamiento de Arendt se ha transformado en una fuente importante de estudio de la biopolítica. Hay una cierta paradoja en la evolución de la recepción del pensamiento de Arendt porque, a primera vista, su pensamiento pareciera defender una estricta separación de la política y de la biología, desde que, en su opinión, ideologías totalitarias como el nazismo son las que reducen la política en biología. Sin embargo, empezando con dos de los más influyentes teóricos contemporáneos de la biopolítica como Giorgo Agamben (1998) y Roberto Esposito (2007), y pasando por artículos recientes de expertos en Arendt, un debate ha surgido en relación a si hay, en el pensamiento de Arendt, las bases para una relación positiva entre la vida biológica y la vida política.

"Vida y política en el pensamiento de Hanna Arendt" de Laura Quintana explora esta cuestión de modo detallado y sistemático. Quintana sostiene que la cuestión de si en el pensamiento de Arendt una política legítima debe excluir la biología, o si, por el contrario, la vida política debe tener una relación interna y positiva con la vida biológica, solo puede ser respondida repasando las diferentes maneras en que Arendt ocupa el concepto de vida. Empezando con Aristóteles y la tradición griega de pensamiento político, el concepto de vida recibe, de hecho, dos significados: la idea de vida biológica genérica compartida por todas las especies animales (designadas por el término zoe), y la idea de una vida humana individualizada llevada a cabo en un espacio político (designada por el término bios). Quintana comienza con una discusión sobre la cuestión de si el pensamiento de Arendt mantiene una división categórica entre vida biológica (zoe) y vida política (bios) tomando en cuenta la lectura que hace Arendt de Aristóteles, quien pareciera sostener esta división. Su análisis muestra que Arendt mantiene una distancia respecto de la idea aristotélica de que el hombre es un animal distinto de todos los otros animales por estar provisto de una naturaleza "política". 
Quintana considera entonces los textos en que Arendt pareciera proyectar la división entre vida política y biológica en la división entre esfera pública y privada, así como los textos en que ella, conocidamente, parece oponer la condición de labor a la condición de acción política, también sobre la base que labor es una necesidad biológica, mientras que la acción es la "verdadera" actividad humana. Pero para Quintana la posición auténtica de Arendt es que la verdadera humanidad del hombre descansa en su búsqueda por la no dominación: las distinciones entre las diferentes dimensiones de la condición humana -lo privado vs. lo público, el labor vs. la acción, la voluntad vs. el pensamiento- permanecen válidas pero no deben ser leídas para implicar que una dimensión domina sobre la otra o es superior. Quintana introduce una distinción entre la crítica de Arendt a la naturalización o zoeficación de la política, versus la pretensión de que la política requiere la exclusión de la zoe. Si Arendt rechaza la naturalización de la política, ella también favorece, según Quintana, a una politización de zoe, haciendo preguntas pertinentes a la vida biológica en temas de debate público.

"Vida y política en el pensamiento de Hanna Arendt" concluye con una consideración de la idea de Arendt de que la vida biológica es una entrega, un regalo, que escapa de la artificialidad de la vida política humana. Este momento del discurso de Arendt es, probablemente, el más complicado y ambiguo: generalmente ha sido interpretado para significar que el ser humano, para ser reconocido como humano, debe tener una identidad política otorgada a él o ella por un Estado nacional -las personas sin estados están condenadas a ser tratadas como carentes de derechos humanos, poseedoras de una vida "básica" que no es merecedora de ser vivida. Pero, si este es el caso, toda identidad política debe requerir la exclusión de diferencias radicales entre los seres humanos, la exclusión de lo que hace a cada uno un ser singular y, como resultado de esto, la formación de la identidad política es necesariamente una forma de dominación. El texto de Arendt sugiere, sin embargo, que si toda alteridad es eliminada, la vida política misma sufrirá y decaerá en una política racista. Dada esta tensión en el pensamiento de Arendt sobre la subjetividad política, Quintana sugiere que una esfera pública necesita ser estructurada para hacer posible que la singularidad de los seres humanos se muestre en su diferencia frente a todos los demás. La autora, coincidiendo con la mirada expresada por Esposito en las entrevistas, sostiene que dicho espacio político no va a permitir la división y exclusión de zoe de bios, de la singularidad biológica de la existencia política. La forma de juntar a estos dos, es a través de la idea de Arendt de la natalidad, entendida como una condición biológica para la existencia política. Por esa razón los textos de Arendt son unas de las articulaciones centrales de la biopolítica y la filosofía, tal como su defensa de la natalidad la transforma en una pensadora de biopolítica afirmativa.

Traducido del inglés por George Lambeth.

\section{REFERENCIAS}

Agamben, Giorio. Homo sacer. Sovereign Power and Bare Life. Stanford California: Stanford University Press.

Esposito, Roberto. 2003. Comunitas: origen y destino de la comunidad. Buenos Aires: Amorrortu Editores. 
Esposito, Roberto. 2005. Inmunitas: protección y negación de la vida. Buenos Aires: Amorrortu Editores.

Esposito, Roberto. 2007. Bios: biopolitica y filosofía. Buenos Aires: Amorrortu Editores.

Habermas, Jürgen. 2001. Die Zukunft der menschlichen Natur. Auf dem Weg zu einer liberalen Eugenik?

Frankfurt: Suhrkamp Verlag.

Negri, Toni. Hardt, Michael. 2000. Empire. Cambridge, Massachusetts: Harvard University Press.

Negri, Toni. Hardt, Michael. 2004. Multitude. War and Democracy in the Age of Empire. London: Penguin Books.

Rancière, Jacques. 2000. Le partage du sensible. Esthétique et politique. Paris: La Fabrique-éditions.

Sloterdijk, Peter. 2009a. Esferas I: Burbujas. Microsferología. Madrid: Siruela.

Sloterdijk, Peter. 2004. Esferas II: Globos. Macrosferología. Madrid: Siruela.

Sloterdijk, Peter. 2009b. Esferas III: Espumas. Esferología plural. Madrid: Siruela.

Vatter, Miguel. 2009. "Biopolitics: From Surplus Value to Surplus Life" in Theory and Event 12:2. En prensa.

Vanessa Lemm es Doctora en Filosofía de la New School for Social Research (EE.UU.), Magíster en Filosofía Analítica del King's College, University of London (Inglaterra). También obtuvo el D.E.A. (Diplome d'Etudes Aprofondis) y la Licenciatura en Filosofía de la Sorbonne, Université de Paris-Panthéon I. Es Profesora Asociada del Instituto de Humanidades de la Universidad Diego Portales, Santiago de Chile. Actualmente es directora del Instituto de Humanidades y del Magíster en Pensamiento Contemporáneo del mismo Instituto. Vanessa Lemm es autora del libro Nietzsche's Animal Philosophy: Culture, Politics and the Animality of the Human Being, New York: Fordham University Press, 2009 y de varios artículos sobre Nietzsche y filosofía política contemporánea. [E-mail: Vanessa. lemm@udp.cl]

Miguel Vatter, es Doctor en Filosofía de la New School for Social Research, EE.UU. Es profesor asociado en la Escuela de Ciencia Política de la Universidad Diego Portales. Es autor de Between Form and Event: Machiavelli's Theory of Political Freedom (Kluwer, 2000) y de El Poder del Pueblo. Ensayos sobre el posmarxismo y el neorrepublicanismo (a publicarse por la editorial de la Universidad Diego Portales). Es editor de Hannah Arendt. Sobrevivir al totalitarismo (LOM, 2008), y de Crediting God: the Fate of Religion and Politics in the Age of Global Capitalism (Fordham University Press, a publicarse en 2009). Sus áreas de investigación y publicación son historia y teoría del republicanismo moderno, biopolítica y teología política. [E-mail: Miguel.vatter@udp.cl] 